\title{
MONITORING OF TOTAL DISSOLVED SOLIDS ON AGRICULTURAL LANDS USING ELECTRICAL CONDUCTIVITY MEASUREMENTS
}

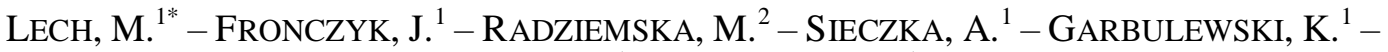 \\ KODA, E. ${ }^{1}-$ LECHOWICZ, Z. ${ }^{1}$ \\ ${ }^{1}$ Department of Geotechnical Engineering, Warsaw University of Life Sciences, \\ Nowoursynowska 159, 02-776 Warsaw, Poland. \\ (phone: +48-22-593-5206; fax: +48-22-593-5203) \\ ${ }^{2}$ Department of Environmental Improvement, Warsaw University of Life Sciences, \\ Nowoursynowska 159, 02-776 Warsaw, Poland. \\ *Corresponding author \\ e-mail: mariusz_lech@sggw.pl; phone: +48-22-593-5206; fax: +48-22-593-5203
}

(Received $11^{\text {th }}$ Jan 2016; accepted $14^{\text {th }}$ Jul 2016)

\begin{abstract}
Soil electrical conductivity measurements are uniquely useful for environmental impact assessment. Both surface and downhole methods may be used to monitor groundwater and soil quality. This paper presents a site investigation that was conducted to characterize soil and groundwater quality in the Imielin countryside in Poland, where traditional and precision farming have been applied. Two methods for estimating the salinity of soils were used: electrical resistivity tomography (ERT) and the EC-Probe for direct measurement of ground salinity. Based on electrical conductivity measurements, several maps of electrical conductivity zones were produced to assess groundwater and soil quality on agricultural land. Moreover, the empirical relationship between total dissolved solids (TDS) in water vs. soil electrical conductivity (EC), moisture and fine particle content was obtained. The two different techniques that were used in this study to measure the electrical conductivity of soil showed comparable test results and demonstrated that the investigated area is not contaminated.
\end{abstract}

Keywords: environmental monitoring, electrical conductivity, ERT, TDS, soil and water salinity

\section{Introduction}

EU directives recommend using the principles of sustainable development for the management of the soil-water environment. It is desirable to ensure a good quality of surface water and groundwater in Europe by 2015. Therefore, the aim of the Nitrates Directive (91/676/EEC) is to protect water quality across Europe, especially from agricultural sources. Good farming practices, for example, precision agriculture management, are among the most effective ways to decrease destructive impacts deriving from agricultural sources. This directive implies the use of variable-rate fertilization to ensure the optimal dose of fertilizer needed for crops and limits the leaching of nitrogen forms from the soil to larger bodies of water (the Baltic Sea), significantly reducing the problem of eutrophication.

Due to a significant increase in agricultural activities and closely associated contamination, there is a need for monitoring, characterization and identification of the soil-water environment. Current methods of environmental soil characterization mainly involve soil sampling and laboratory analysis. Furthermore, geophysical methods for obtaining soil electrical conductivity measurements have also been applied in soil and water monitoring to identify contaminated zones and establish a relationship between electrical conductivity and the presence of pollutants. Soil electrical conductivity is an 
indirect measurement that correlates very well with several soil physical and chemical properties, for example, soil moisture and ion concentration in water solution.

The electrical conductivity of soil strictly depends on the soil salinity; therefore, based on electrical conductivity measurements, it is possible to determine soil salinization and identify contaminated zones. Salinization could be considered an increased salt concentration of the soil and is most often related to the development and expansion of agricultural practices. The increased occurrence of salt in soil significantly impacts the environment, mainly degrading crop productivity and soil quality by reducing the ability of crops and plants to take up water and leading to lower yields, which are responsible for serious economic losses in agricultural production (Zaldis et al., 2002; Dube and Chitiga, 2011). It should be emphasized that too much salt of any type is detrimental to plants and other organisms.

Salinization also has an indirect effect, leading to the loss of soil stability through changes in soil structure. Moreover, leaching salts from the soil can easily cause the saline water to eventually enter groundwater basins. Thus, measuring soil salinity can be considered a reliable way to assess the range of salinization impact on plant growth. According to many authors (Gartley, 2011; Hardie and Doyle, 2012), salinity could be divided into several classes signifying the range of soil salinization (Table 1). Harmful effects of soil salinity can also be determined according to the scale presented by Jakubiak (2010) (Table 2).

Table 1. Soil salinity classes (Jakubiak, 2010)

\begin{tabular}{c|c}
\hline Salinity class & EC $[\mathbf{m S} / \mathbf{m}]$ \\
\hline Non-saline & $0-200$ \\
Slightly saline & $200-400$ \\
Moderately saline & $400-800$ \\
Highly saline & $800-1600$ \\
Extremely saline & $>1600$ \\
\hline
\end{tabular}

Table 2. Soil salinity and its interpretation (Jakubiak, 2010)

\begin{tabular}{c|l}
\hline $\begin{array}{c}\text { Soil salinity } \\
{[\mathbf{m S} / \mathbf{m}]}\end{array}$ & \multicolumn{1}{c}{ Interpretation } \\
\hline$<50$ & $\begin{array}{l}\text { Concentration tolerated by all plant species } \\
50-100\end{array}$ \\
$100-200$ & $\begin{array}{l}\text { The limit values for sensitive plants } \\
\text { Symptoms of salinity for many plant species; harmful concentration for many } \\
\text { plant species during the drought period } \\
\text { Toxic concentration for almost all plant species }\end{array}$ \\
\hline 200 &
\end{tabular}

Moreover, if excess nitrate fertilizer is applied to a field, the nitrate that is not used by plants can dissolve in porewater and move to groundwater, increasing its salinity level. An excellent indicator of groundwater salinity is the total dissolved solids (TDS), describing the inorganic salts and small amounts of organic matter that are present in water (e.g. Pozdnyakowa et al., 2001). The most commonly used method of determining TDS in water supplies is the measurement of specific conductivity with a conductivity probe that detects the presence of ions in water. Conductivity measurements are converted into TDS values by means of a factor that varies with the type of water (ISO 7888, 1985; Singh and Kalra, 1999). According to WHO guidelines for drinking water quality (1996), water with a TDS above $500 \mathrm{mg} / \mathrm{L}$ is not recommended for use as 
drinking water. Water with a TDS above 1,500 to 2,600 mg/L (EC greater than 225 to $400 \mathrm{mS} / \mathrm{m}$ ) is generally considered problematic for irrigation use on crops with a low or medium salt tolerance.

\section{Material and Methods}

\section{Characteristics of the test area}

The test area is located in the central part of Poland in the Imielin countryside. Geologically, the area lies within the Vistula River Valley, within the geomorphological unit termed the Warsaw Basin. The Quaternary basement comprises lake deposits of the youngest stage of the Tertiary - Pliocene, developed as clays, silty clays, silts, and locally silty sands - referred to as the motley clays. These deposits are distinguished in the topmost part of the regional tectonic unit called the Mazovian Basin.

Alluvial deposits occurring within the Vistula Valley form two structural elements. The first element includes a set of Pleistocene terraces that developed during the Vistulian Glaciation. The second structural element is the flood terrace with the Holocene horizon - developed by the meandering Vistula and the present-day terrace formed by a braided river.

The test area was additionally characterized by fourteen drillings to identify geological and hydrogeological conditions. Based on the drillings, it was found that below the layer of top soil with humus (a thickness up to $0.6 \mathrm{~m}$ ), cohesive soils (silts and clays) occur to a depth of approximately $2.5 \mathrm{~m}$. Below this layer, a permeable layer of medium and silty sands was found, with the groundwater table at a depth of $2.7 \mathrm{~m}$ below the ground surface.

\section{Electrical conductivity measurements}

This study was conducted as part of a larger research effort to assess the impact of precision agriculture on the soil and groundwater environment. In this study, we measured the vertical and horizontal distribution of bulk soil conductivity and the specific conductance of water. Our objectives were to (1) determine the soil salinity changes over a longer period of time (one vegetative period) depending on environmental conditions and the type of agricultural practice (traditional agriculture constant dose of fertilizer, or precision agriculture - adjusted dose of fertilizer), (2) determine the relationship between soil conductivity measurements obtained from field investigations and TDS laboratory tests of water using piezometers and lysimeters, and (3) assess the porewater and groundwater quality under in situ conditions.

The bulk electrical conductivity of the soil can be considered as a proxy for the spatial and temporal variability of many other soil physical properties, i.e., structure, water content or fluid composition (Zahody et al., 1974; Samouelian et al., 2005). The electrical conductivity of the soil may be determined with a direct or alternating (low frequency) current, in which the current is applied at two locations, and the potential (voltage) difference is measured between two points. This method is non-destructive and very sensitive and offers a very attractive tool for describing the subsurface properties without drilling; it has been already applied in various contexts, including groundwater exploration, landfill and solute transfer delineation, and the compaction and hydrogeological properties of soils (Archie, 1943; Zahody et al., 1974; Samouelian et al., 2005; Lech et al., 2008; Reynolds, 2011; Lowrie, 2014). The apparent soil 
electrical conductivity has also become one of the most reliable and frequently used measurements to characterize field variability for application in precision agriculture (Allred, 2008). Soil resistivity is mainly influenced by the type of soil (clay, quartz, etc.), moisture content, amount of electrolytes (minerals and dissolved salts) and temperature (e.g. Reynolds, 2011; Lowrie, 2014). To obtain the physical and chemical properties of soil using electrical methods, several techniques can be effectively used: (1) the self-potential method (SP), (2) the four-electrode method (Vertical Electrical Sounding, Electrical Resistivity Tomography), (3) electromagnetic conductometers (EM) and (4) invasive techniques (RCPTU- resistivity cone penetration tests, EC conductivity/salinity probe).

In this study, to determine the levels of soluble salts in the soil and water, in situ and laboratory investigations were carried out. Data were collected from a field survey using 2-D electrical resistivity tomography (ERT) and an EC-Probe (Fig.1). The ERT was carried out using the Wenner electrode array configuration. The Wenner array consists of four collinear, equally spaced electrodes. The outer two electrodes are typically the current electrodes, and the inner two electrodes are the potential electrodes. The current (I) is applied to the two outer electrodes (A and B) and the arising difference in potential $(\Delta \mathrm{U})$ is measured between the two inner electrodes $(\mathrm{M}$ and $\mathrm{N})$. The electrical resistivity (ER) is calculated from the Ohm's law as:

$$
E R=K \frac{\Delta U}{I}
$$

where $K$ is a geometrical factor [m] depending on the distance between the electrodes, $\Delta U$ is the difference in potentials [V], and $I$ is the magnitude of current [A].
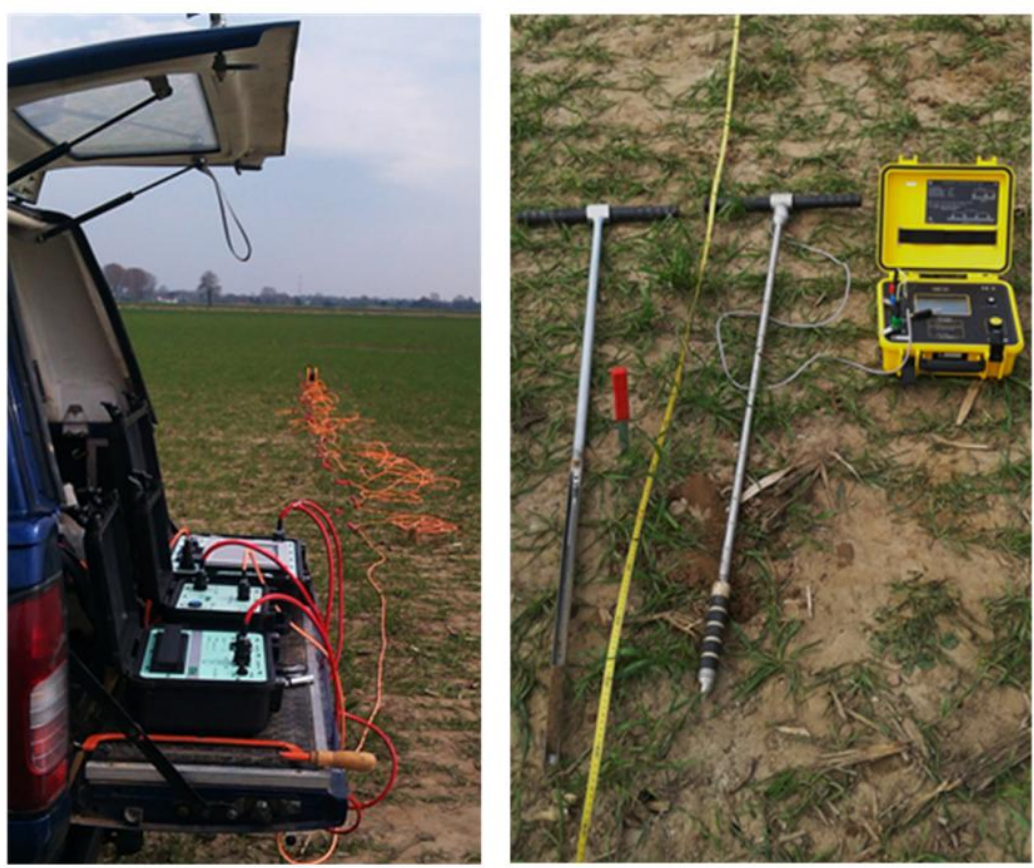

Figure 1. Electrical resistivity tomography (ERT) survey line (on the left) and EC-Probe measurements (on the right) 
The surveys were carried out using a resistivity meter that was equipped with a multicore cable and 32 electrodes. The length for 3 survey lines with 32 electrodes was 15 and 70 meters and reached a depth of 2.75 and 14 meters in the central parts of the measured sections. The second field method was the EC-Probe for salinity measurements. This probe consists of a stainless steel rod with $0.1 \mathrm{~m}$ graduation and a detachable handle. The probe has four electrodes, each separated by a sealing and insulation ring, and a temperature sensor. The outer electrodes are current electrodes, and the inner electrodes are measuring electrodes. Upon measuring the electrical resistivity $(\mathrm{ER})$ and determining the temperature correction factor $\left(\mathrm{f}_{\mathrm{t}}\right)$, the soil electrical conductivity (EC) can be calculated according the formula below:

$$
E C=K \frac{f_{t}}{E R}
$$

where $E C$ is the soil electrical conductivity in $[\mathrm{mS} / \mathrm{cm}]$ at $25^{\circ} \mathrm{C}, K$ is the empirically established cell constant $\left[\mathrm{cm}^{-1}\right]\left(17.5 \mathrm{~cm}^{-1}\right), f_{t}$ is the temperature correction factor for converting the measured $E C$ to the $E C$ at $25^{\circ} \mathrm{C}$ [-], and $E R$ is measured resistivity at the prevailing temperature in $[\Omega]$.

Dissolved salts largely affect the electric conductivity of the soil. Because conductivity is measured directly under in situ conditions, the measured value stands for bulk soil conductivity (mineral body and pore water). Only after the extraction of the pore water (by soil moisture sampling) can we measure the EC of pore water alone. Thus, the SDEC ceramic lysimeters were installed into the field to collect the soil water that moves along the soil profile. These lysimeters consist of a porous ceramic cup fixed to the bottom of an empty PVC tube. After creating a depression inside the tube (with vacuum pump), the tube was placed into the soil at a depth of $0.3 \mathrm{~m}$. The soil solution was drawn out of the soil trough the porous ceramic cup into the tube. The soil solution was analysed with a laboratory analyser (YSI Professional Plus, USA) that was equipped with a combined electrode to measure the reference values of conductivity, $\mathrm{pH}$, temperature, salinity and oxidation-reduction potential.

\section{Results and Discussion}

In this study, two cross-sections that were obtained using electrical resistivity tomography (ERT) method are discussed. The electrical conductivity cross-sections in the northwest part of the field are shown in figure 2 . The first of the sections is more general and covers the ground to a depth of 14 meters. From the ground to a depth of approximately 3.5 to $4.5 \mathrm{~m}$, the electrical conductivity values oscillate from 25 to $35 \mathrm{mS} / \mathrm{m}$ (it gives approx. ER $30 \Omega \mathrm{m}$ ), which may indicate the presence of cohesive soils in this area. This presence was confirmed by drilling results to install piezometers. Below this layer is a soil layer with a conductivity from 6 to approx. $16 \mathrm{mS} / \mathrm{m}(60$ $160 \Omega \mathrm{m})$. This value suggests the presence of a non-cohesive layer of medium and coarse sands with gravel. It may be concluded that this layer is located below the water table. The second section is more detailed and is located between 0 and $15 \mathrm{~m}$ in the first cross-section. This shallow cross-section shows that, to a depth of approximately $1.2 \mathrm{~m}$, the conductivity values range between 5 and $15 \mathrm{mS} / \mathrm{m}$, and this layer is formed by clayey sands. The differences in conductivity in this layer could be caused by the fines content, water content and salinity of the pore fluid. Below this layer, at a depth of 
$1.2 \div 2.75 \mathrm{~m}$, the conductivity is approximately $20 \div 40 \mathrm{mS} / \mathrm{m}$, which represents clays. In the left part of the cross-section, from a depth of $1.6 \mathrm{~m}$ to $2,75 \mathrm{~m}$ is a layer that is characterized by a conductivity of $50 \div 100 \mathrm{mS} / \mathrm{m}(10 \Omega \mathrm{m})$, indicating the presence of high-plasticity clays. The EC-Probe direct measurements that were conducted in this location also show that at a depth from 1.3 to $1.6 \mathrm{~m}$, the electrical conductivity ranges from $47 \div 128 \mathrm{mS} / \mathrm{m}$ and increases with depth (Fig. 2).
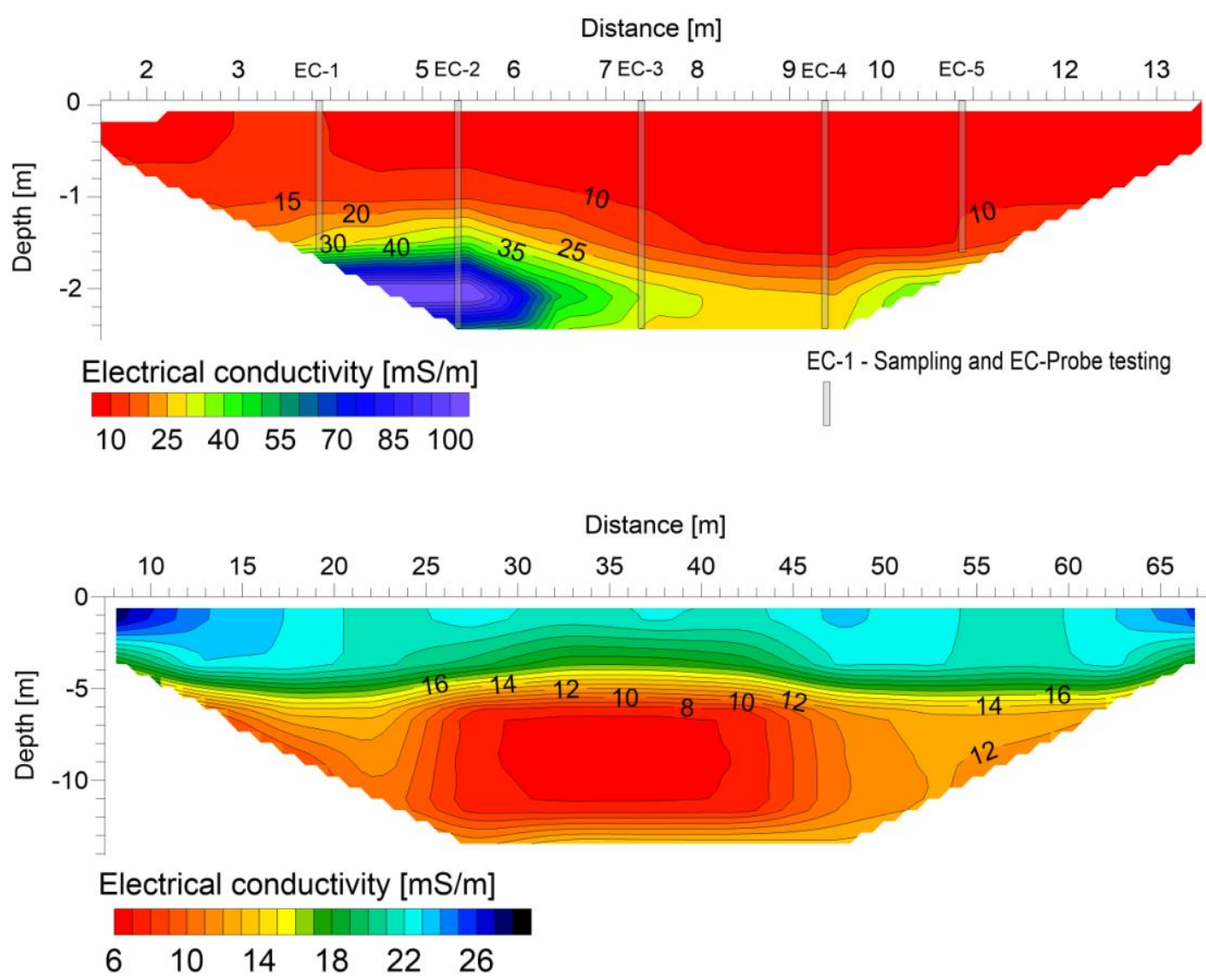

Figure 2. Electrical conductivity cross-sections in Imielin based on Electrical Resistivity Tomography measurements

Based on the laboratory investigations made in previous years on medium and coarse sands (Lech, 2006) and assuming that the formation factor (FF) of sands occurring in Imielin is between 5 and 7 , it can be concluded that the electrical conductivity of groundwater in the aquifer zone ranges from 45 to $83 \mathrm{mS} / \mathrm{m}(450 \div 830 \mu \mathrm{S} / \mathrm{cm})$. According to Polish standards (Polish Journal of Laws no. 143 pos. 896, 2008) the electrical conductivity of groundwater corresponds to water quality classes I or II and III. Furthermore, according to the cited standards, the range of electrical conductivity between 200 and $700 \mu \mathrm{S} / \mathrm{cm}$ may constitute a geochemical background, indicating the absence of anthropogenic impacts on groundwater. Using the well-known equation (e.g. Atekwana et al., 2004) and considering that the correlation coefficient ke is 0.65 , it can be found that the TDS for groundwater from the Imielin countryside varies between 290 and $540 \mathrm{mg} / \mathrm{L}$.

In the next stage of in situ testing, the soil conductivity using the EC-Probe was examined. Figure 3 shows the changes in soil electrical conductivity measured at a 
depth of $0.3 \mathrm{~m}$. In Figure 3, there is a significant difference between the values of EC within the investigated area. It appears that in the N-W direction, the values of EC are slightly lower. Due to the soil water content variability associated with the direction of groundwater flow (from S-E to N-W direction) and elevation, it was expected that the values of EC will be higher than in the other parts of the investigated area. The values of soil electrical conductivity range between 5 and $8 \mathrm{mS} / \mathrm{m}$, while in the $\mathrm{S}$-E direction, they are more than $14 \mathrm{mS} / \mathrm{m}$. Moreover, according to Tables 1 and 2 and considering the results that are presented in Figures 2 and 3, there is no salt contamination in the investigated area.

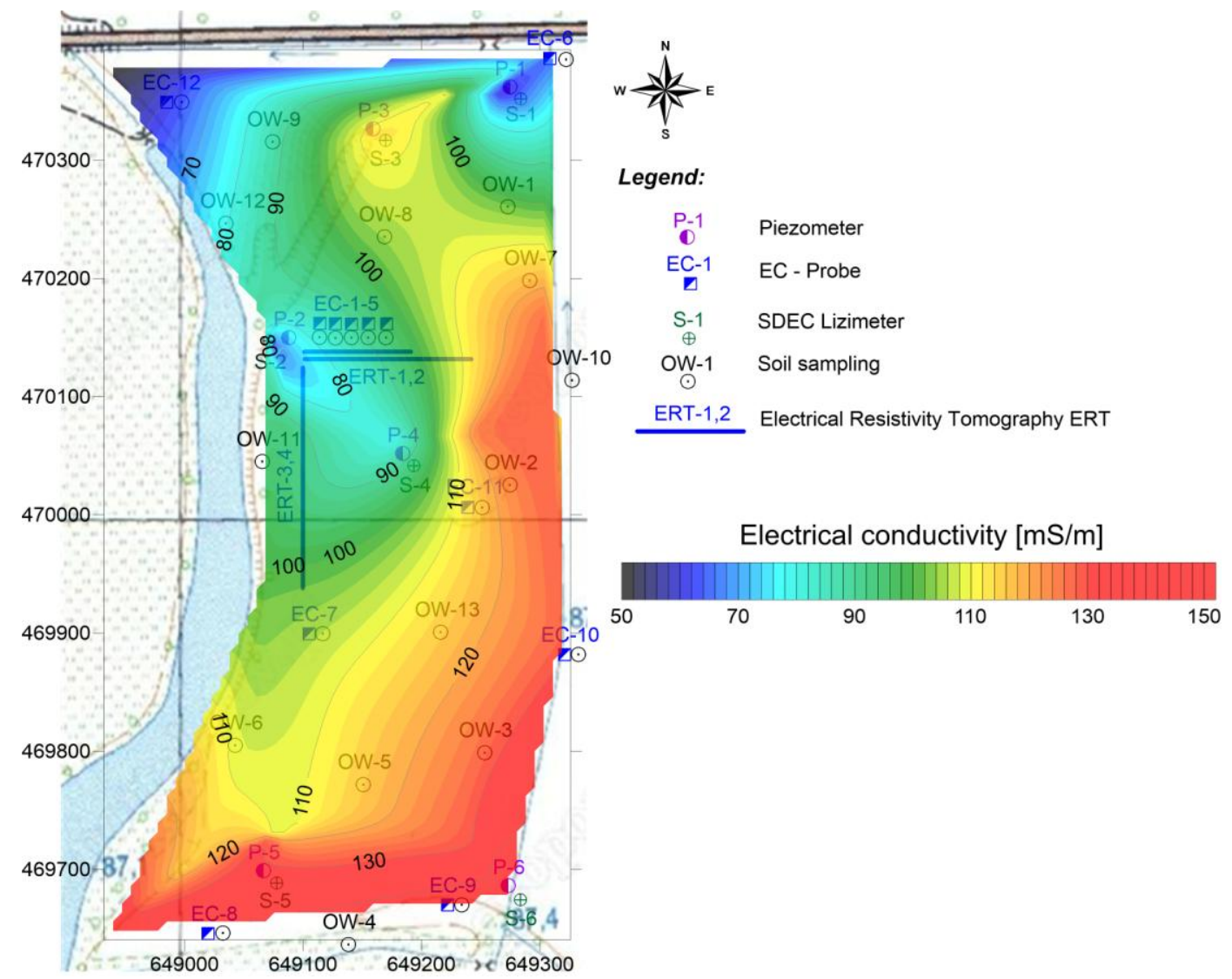

Figure 3. Electrical conductivity map based on EC-Probe measurements and location of in situ tests in Imielin

Factors that significantly impact the measured EC values include the water content and soil type (percentage of well conductive minerals). For this purpose, 107 soil samples were collected to evaluate the differences in these parameters within the field. Figure 4 presents changes in the water content and the content of grain fraction less than $0.063 \mathrm{~mm}$ at a depth of $0.3 \mathrm{~m}$. The soil moisture corresponds to the content of fines and, in combination with the salinity of pore fluid, could affect the recorded EC values.

The tests results indicate the possibility of estimating the TDS of water contained in soil pores based on the electrical conductivity of soil, its water content and fines (less than $0.063 \mathrm{~mm}$ ). The following relationship that is suggested for clayey sands will be helpful in estimating the TDS characteristics without the need for water sampling, 
which is a problem from the point of view of lysimeter installation and subsequent laboratory tests. TDS can be expressed as:

$$
\mathrm{TDS}=3,35 \cdot \mathrm{EC} \cdot \mathrm{w} 0.5 \cdot \mathrm{FC}\left(\mathrm{R}^{2}=68 \%\right)
$$

where TDS is the total dissolved solids in water [mg/L], EC is the electrical conductivity of soil $[\mu \mathrm{S} / \mathrm{cm}], w$ is the water content [-], and $F C$ is the fines $(<0.063 \mathrm{~mm})$ content [-].
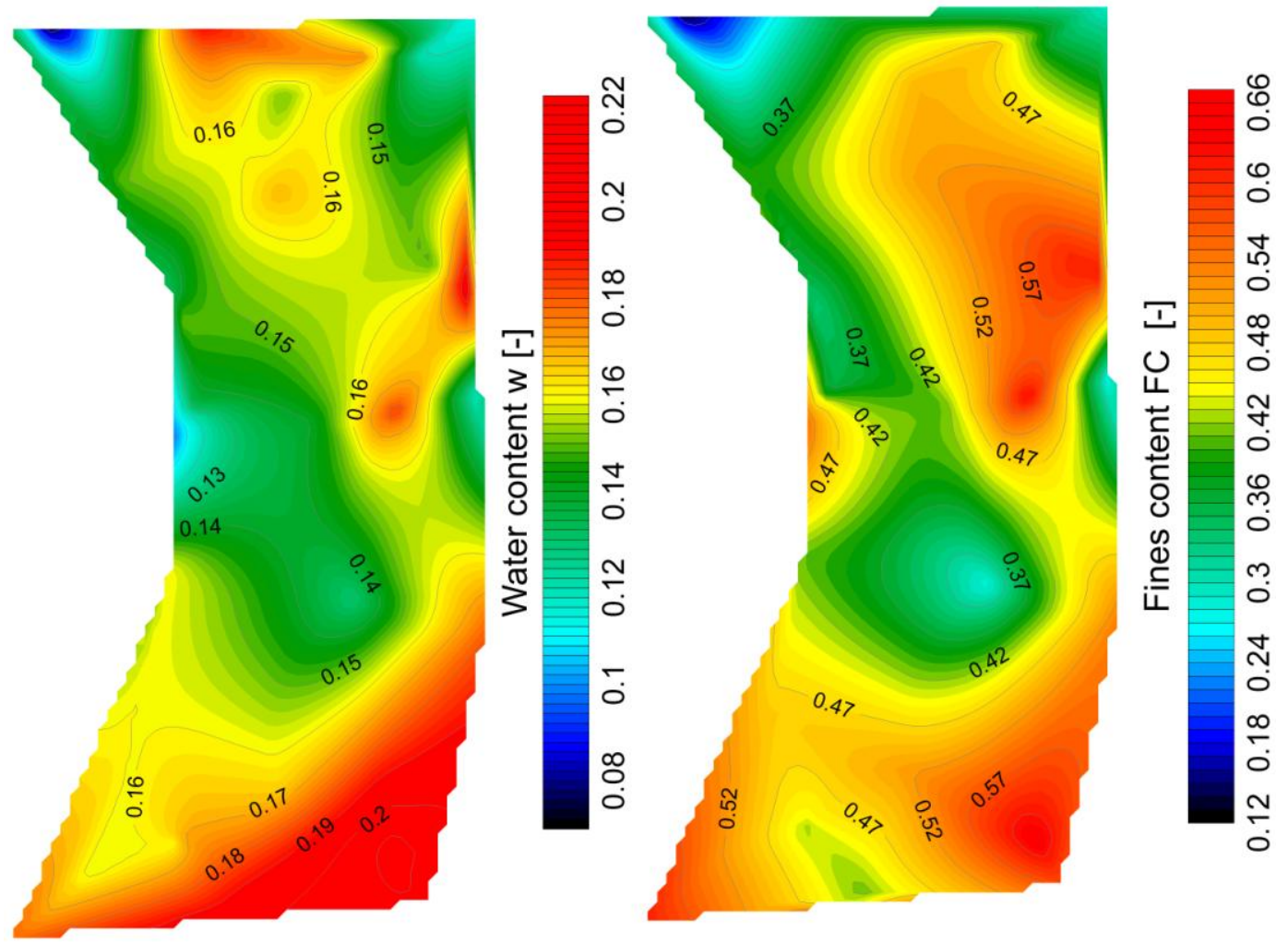

Figure 4. Distribution of water content and fines content in Imielin

The response surface plot for the proposed relationship is shown in Figure 5.

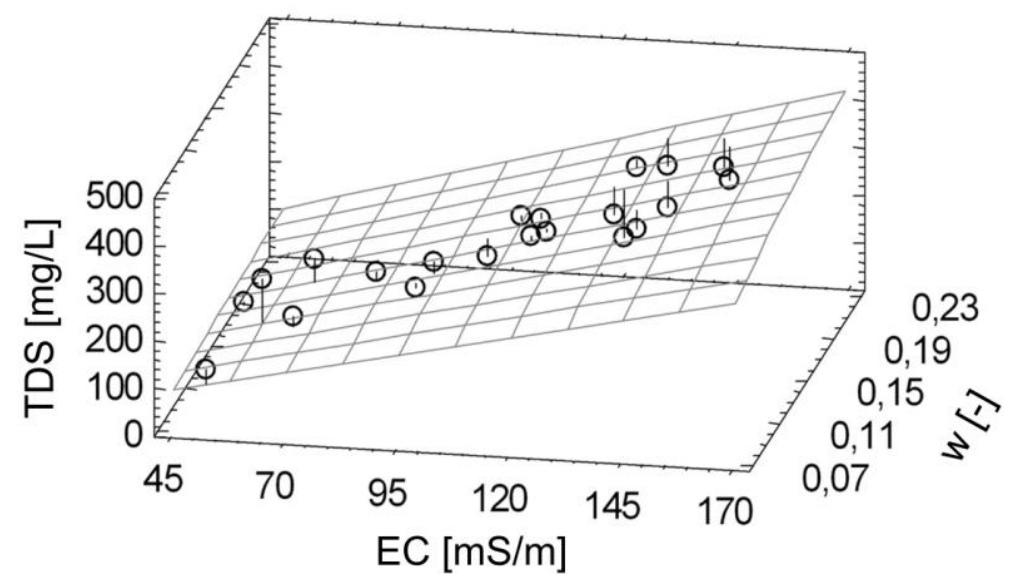

Figure 5. The response surface plot for the proposed relationship 
The following graph (Fig. 6) illustrates the TDS reference values that were obtained from laboratory measurements on water samples from lysimeters and the calculated values of TDS according to the proposed formula. Both graphs indicate that in the N-W part of an object are the highest values of TDS. There is a good correlation between the electrical conductivity, water content and fines content. In zones with a small amount of fine particles and low moisture, small values of TDS were also reported. These results indicate the possibility of the leaching of salts derived from fertilization in these areas deeper into the soil profile. The highest values of measured TDS were recorded in the $\mathrm{S}-\mathrm{W}$ part of the investigated area (approx. $300 \mathrm{mg} / \mathrm{L}$ ), while the highest calculated values were registered in the $\mathrm{S}-\mathrm{E}$ part (approx. $320 \mathrm{mg} / \mathrm{L}$ ).

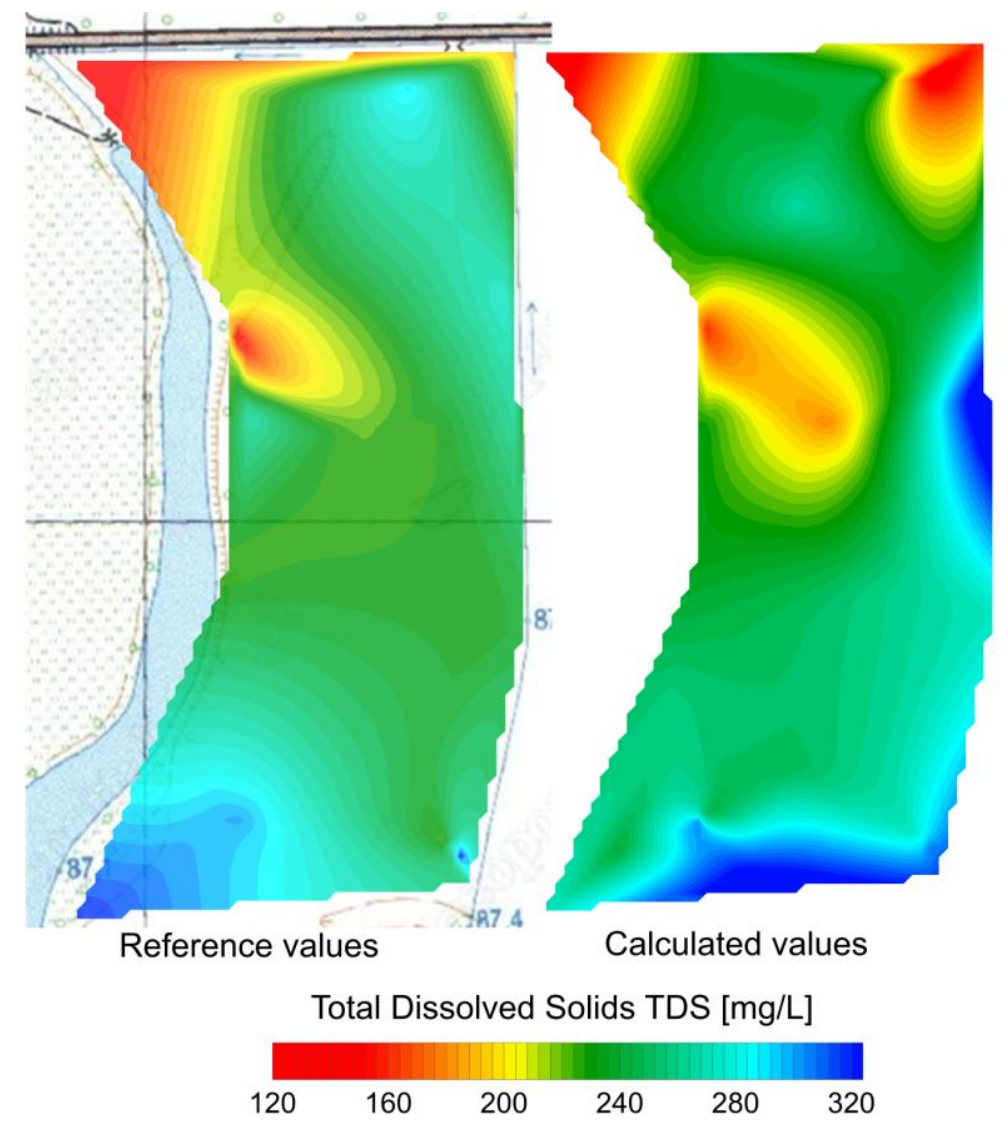

Figure 6. The reference and calculated values of TDS in Imielin

The results of the total dissolved solids analysis that was carried out in the laboratory show a good agreement with the values calculated according to (Eq.3) (Fig. 6). Thus, the TDS estimation according to the proposed formula provides reliable data, which may have a number of applications. The data can also be used to monitor the impact of natural and farm management factors on the extent of visible salinity.

It seems reasonable to use the mapping of electrical soil properties to discover the heterogeneity of soil. The ability to obtain high-resolution maps of soil electrical conductivity at different levels could be helpful to assess the impact of agricultural uses of land and to classify soil and water salinity. 


\section{Conclusions}

Electrical conductivity measurements can be commonly used both in geotechnical engineering and precision agriculture as a very effective tool for creating spatially dense datasets to describe the soil variability within a field. Based on electrical conductivity measurements, it is possible to create electrical conductivity maps that could have a wide application in environmental and agricultural management, for example, in contamination identification, yield map interpretation, soil sampling within more accurate soil boundaries, and deriving input recipes for nutrients, seeds and herbicides.

The procedures that are presented in this paper for measuring soil salinity may be considered relatively simple tools to assess the solute transfer delineation in an agricultural area. The two different techniques that were used in this study to measure the electrical conductivity of the soil show no differences in the measured values, which is crucial in further interpreting test results. Laboratory and field methods that are commonly used for soil salinity determination are highly dependent on soil properties, such as texture, moisture and measuring conditions. It is necessary to identify all of these factors before applying any of the methods that are mentioned in this paper.

The results that were obtained from the laboratory EC measurements for samples that were taken from the Imielin site and in situ tests demonstrate that the test area is not contaminated with salts and thus can ensure favourable conditions for crops.

Acknowledgements. This research was co-financed by the European Regional Development Fund under the Innovative Economy Operational Programme: BIOPRODUCTS, innovative production technologies of pro-healthy bakery products and pasta with reduced caloric value - POIG.01.03.01-14-041/12.

\section{REFERENCES}

[1] Allred, B.J., Daniels, J.J., Ehsani, M.R. (2008): Handbook of. Agricultural Geophysics. CRC Press, Taylor and Francis Group. New York.

[2] Archie, G.E. (1942): The electrical resistivity log as an aid in determining some reservoir characteristics. - Transactions of the American Institute of Mining and Metallurgica Engineers 146: 54-61.

[3] Atekwana, E.A., Atekwana, E.A., Rowe, R.S., Werkema, D.D, Legall, F.D. (2004): The relationship of total dissolved solids measurements to bulk electrical conductivity in an aquifer contaminated with hydrocarbon. - Journal of Applied Geophysics 56: 281- 294.

[4] Dube, T., Chitiga, M. (2011): Human impacts on macrophyte diversity, water quality and some soil properties in the Madikane and Dufuya Wetlands of Lower Gweru, Zimbabwe. - Applied Ecology and Environmental Research 9(1):85-99.

[5] Gartley, K.L. (2011): Recommended methods for measuring soluble salts in soils. Northeastern Regional Publication No. 493, 3rd Ed. The Northeast Coordinating Committee for Soil Testing (NEC-1012).

[6] Hardie, M., Doyle, R. (2012): Measuring soil salinity. - Methods in Molecular Biology 913: 415-425.

[7] Jakubiak, M. (2010): The Application of laser biostimulation to increase salty soil reclamation capabilities of selected plant species. - AGH, Kraków (in Polish).

[8] Keller, G.V., Frischknecht, F.C. (1966): Electrical methods in geophysical prospecting. Pergamon Press, Oxford.

[9] Lech, M. (2006): The application of electrical resistivity method to recognize the groundwater flow conditions. - PhD thesis, Department of Geotechnical Engineering, Warsaw University of Life Sciences - SGGW (in polish).Warsaw. 
[10] Lech, M., Bajda, M., Markowska-Lech, K. (2008): The use of resistivity and seismic cone penetration tests for site characterization. - Annals of Warsaw University of Life Sciences - SGGW. Land Reclamation 40: 87-96.

[11] Lowrie, W. (2014): Fundamentals of Geophysics (2-nd edition). - Cambridge University Press. Cambridge.

[12] Pozdnyakova, L., Pozdnyakov, A., Zhang, R. (2001): Application of geophysical methods to evaluate hydrology and soil properties in urban areas. - Urban Water 3:205-216. London.

[13] Reynolds, J.M. (2011): An introduction to applied and environmental geophysics. - John Wiley and Sons Ltd. New York.

[14] Rhoades, J.D., Chanduvi, F., Lesch, S. (1999): Soil salinity assessment. Methods and interpretation of electrical conductivity measurements. - FAO Irrigation and Drainage Paper No. 57: Food and Agriculture Organization of the United Nations. Rome.

[15] Samouelian, A., Cousin, I., Tabbagh, A., Bruand, A., Richard, G. (2005): Electrical resistivity survey in soil science. - Soil and Tillage Research 83: 173-193.

[16] Singh, T., Kalra, Y.P. (1999): Specific conductance method for in situ estimation of total dissolved solids. - Journal of the American Water Works Association 67(2).

[17] Zahody, A.A.P., Eaton, G.P., Mabey, D.R. (1974): Electrical methods in US Geological Survey. Ch. 2: Application of surface geophysics to ground - water investigations. Technical Water Resources, USGS Publications.

[18] Zalidis, G., Stamatiadis, S., Takavakoglou, V., Eskridge, K., Misopolinos, N. (2002): Impacts of agricultural practices on soil and water quality in the Mediterranean region and proposed assessment methodology. - Agriculture, Ecosystems \& Environment 88(2): $137-146$.

[19] 91/676/EEC (1991): Council Directive concerning the protection of waters against pollution caused by nitrates from agricultural sources.

[20] ISO7888:1985 (1985): International Organization for Standardization. Water quality determination of electrical conductivity. Geneve.

[21] Guidelines for drinking-water quality 2nd ed. Vol. 2. Health criteria and other supporting information (1996): World Health Organization, Geneve.

[22] Regulation of the Minister of Natural Environment on the criteria and method of quality assessment of groundwater (2008): - Dz.U. 2008 Nr. 143 poz. 896. 